\title{
Undiagnosed acute phase endobronchial tuberculosis with progression to irreversible tracheobronchial stenosis
}

\author{
Hazrini Abdullah, ${ }^{1}$ Chu Zhen Quek ${ }^{2}$
}

'Department of Radiology, Hospital Sultanah Aminah, Johor Bahru, Malaysia

${ }^{2}$ Cardiology Department Hospital Sultanah Aminah, Johor Bahru, Johor, Malaysia

Correspondence to Dr Hazrini Abdullah, hazrini@hotmail.com

Accepted 20 July 2017
CrossMark

To cite: Abdullah $\mathrm{H}$, Quek CZ. BMJ Case Rep Published Online First: [please include Day Month Year]. doi:10.1136/bcr-2017219877

\section{DESCRIPTION}

This case report highlights the challenges in diagnosing the rare endobronchial tuberculosis (EBTB) during the acute phase. The diagnostic dilemma escalated due to the fact that once airway stenosis has developed, it is irreversible and imposes significant morbidity and mortality.

We present a young Chinese woman in her twenties presented to the emergency department (ED) with noisy breathing and breathlessness. She was diagnosed with probable pulmonary tuberculosis (TB) with positive Mantoux and sputum examination for acid-fast bacilli and was started on anti-TB treatment a month prior. In ED, she was breathless, but the oxygen saturation was 95\% under room air with normal vital parameters. Auscultations and chest radiograph were unremarkable. Upper airway assessment by the ear,

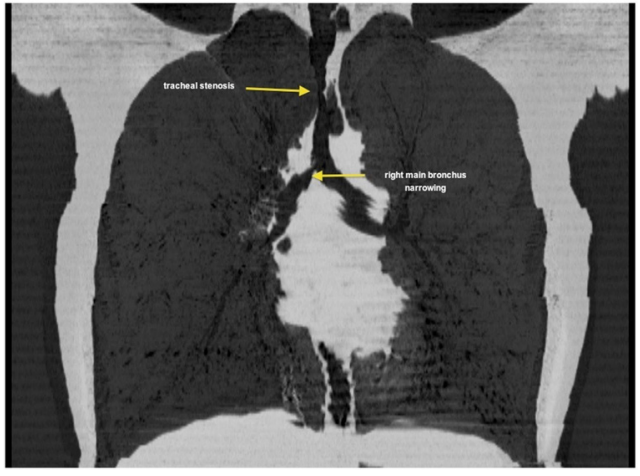

Figure 1 Coronal view of reconstructive minimum intensity projection image showing tracheal stenosis narrowest at T4 level and narrowing in the right main bronchus.

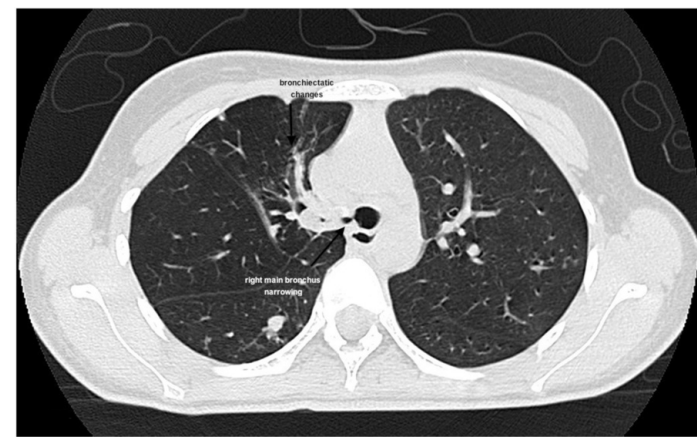

Figure 2 Axial image in lung window revealed the right main bronchus narrowing with bronchiectatic changes in the anterior segment of the right upper lobe.

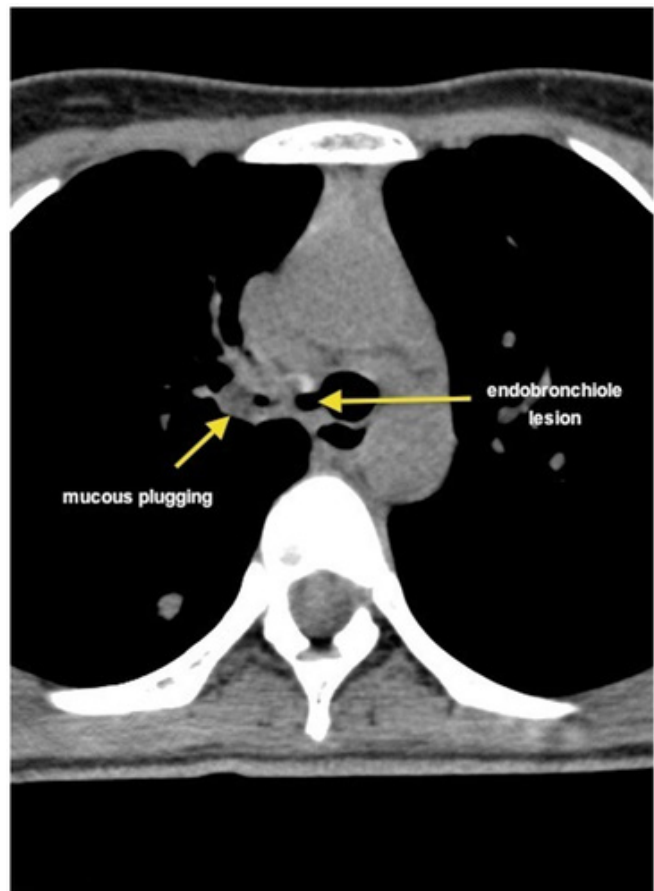

Figure 3 Axial image in mediastinal window depicted the right main bronchus endoluminal lesion with mucous plugging distally.

nose and throat surgeon was normal. High-resolution (HR) CT thorax was performed in view of mild occasional stridor observed in the ward (figure 1). The HRCT revealed airway narrowing with bronchiectasis (figure 2) and mucous plugging (figure 3). Bronchoscopy performed showed
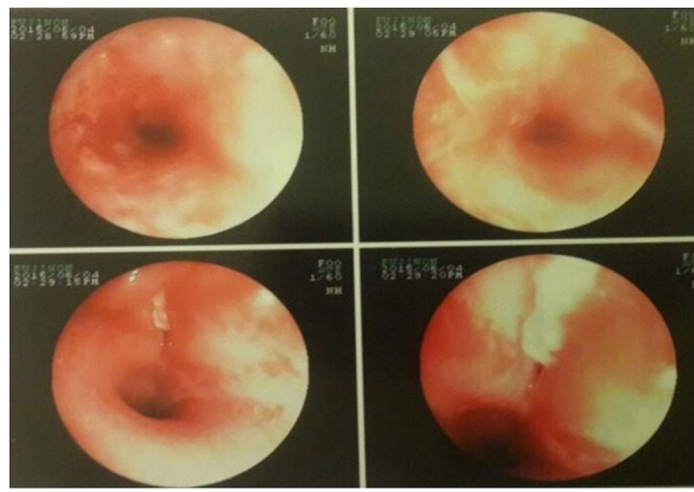

Figure 4 Bronchoscopy images with upper row showing trachea luminal narrowing and the bottom row showing caseating lesion at the right main bronchus. 


\section{Learning points}

- Endobronchial tuberculosis (EBTB) is not often seen in the population nowadays after the advent of antituberculous therapy, and in most cases, it is associated with pulmonary tuberculosis. It has a special predilection for young female and geriatric population. ${ }^{1}$

- Recognition of EBTB with subtle clinical presentation during acute phase is important because once significant stenosis has occurred, it is irreversible by antituberculous therapy and is life threatening.

- The definite diagnosis of EBTB is by high-resolution computed tomography and bronchoscopy with histopathological examination, the latter having additional prognostication value.

caseating lesion in the right main bronchus (figure 4). Tracheal dilatation and mycotin injection were performed. Histopathological examination was suggestive of tuberculosis and confirmed by the culture.

The initial diagnosis of EBTB is a challenge. Furthermore, EBTB is known to have low sputum yield of $16 \%-53 \% .^{12}$ The definite diagnosis of EBTB is by HRCT and bronchoscopy, the latter having additional prognostication value. ${ }^{3}$ Chung classified EBTB into seven bronchoscopic subtypes: actively caseating, fibrostenotic, edematous-hyperaemic, tumorous, ulcerative, granular and non-specific bronchitic. ${ }^{1}$ The caseating type was seen in this case.

Contributors Both authors contributed to the initial idea of the writing of the manuscript. The report and design of the manuscript were done by both authors. Reconstruction of the images and description done by HA.

Competing interests None declared.

Patient consent Obtained.

Provenance and peer review Not commissioned; externally peer reviewed.

(C) BMJ Publishing Group Ltd (unless otherwise stated in the text of the article) 2017. All rights reserved. No commercial use is permitted unless otherwise expressly granted.

\section{REFERENCES}

1 Chung HS, et al. Classification of endobronchial tuberculosis by the bronchoscopic features. Tuberc Respir Dis 1991;38:108-15.

2 Ozkaya S, Bilgin S, Findik S, et al. Endobronchial tuberculosis: histopathological subsets and microbiological results. Multidiscip Respir Med 2012;7:34

3 Kashyap S, Solanki A. Challenges in endobronchial tuberculosis: from diagnosis to management. Pulm Med 2014;2014:1-8

Copyright 2017 BMJ Publishing Group. All rights reserved. For permission to reuse any of this content visit http://group.bmj.com/group/rights-licensing/permissions.

BMJ Case Report Fellows may re-use this article for personal use and teaching without any further permission.

Become a Fellow of BMJ Case Reports today and you can:

- Submit as many cases as you like

- Enjoy fast sympathetic peer review and rapid publication of accepted articles

- Access all the published articles

- Re-use any of the published material for personal use and teaching without further permission

For information on Institutional Fellowships contact consortiasales@bmjgroup.com

Visit casereports.bmj.com for more articles like this and to become a Fellow 